\title{
Digital Scanning Radiographic Image Analysis of Alveolar Bone Loss in Individuals with Untreated Adult Periodontitis and Aggressive Periodontitis: A Cross-Sectional Study
}

\author{
Guey Lin Hou ${ }^{1,2 *}$ \\ ${ }^{1}$ Former Professor, Graduate Institute of Dental Science, Periodontics, Kaohsiung Medical University, Taiwan \\ ${ }^{2}$ Former Professor, Dental Department of Kaohsiung Chang-Gang Memorial Hospital, Taiwan
}

Submission: December 10, 2020; Published: December 21, 2020

*Corresponding author: Guey-Lin Hou, Former Professor of Graduate Institute of Dental Science, Periodontics, Kaohsiung Medical University, Kaohsiung, Taiwan

Abstract

The purpose of the present investigation was to evaluate the difference of radiographic alveolar bone loss (RABL) in Taiwan Chinese subjects with aggressive periodontitis (AgP) and adult periodontitis (AP) using the digital scanning radiographic image analysis (DSRIA). A total of 4262 teeth were examined in 178 individuals comprising 96 males and 82 females for the RABL of the AGP and the AP. Subject pooling sample with $\mathrm{AgP}$ and a compared group, AP, were originally identified from the Periodontal Clinic population (College of Dental Medicine, Kaohsiung Medical University). The following criteria were used to classify subjects with AgP and AP for the past 20 years. The method used to document mesial and distal sites included periapical radiographs, scanner, computerized programs system equipped with the Microstation 95 Image software. All the RABL of teeth were calculated by a computer system equipped with Microstation 95 software under a 10x magnification of radiograph. Quantity assessment of RABL using the DSRIA showed that: (1) the means of RABL of maxillary and mandibular anterior teeth in the AgP group were significant greater than those in the AP group when two sample t-test was used; (2) the greatest values of mean RABL of affected sites with AgP group occurred most common in the first molars and mandibular incisors; whereas the AP group occurred most common in the first and second molars; (3) the mean RABL in a descending order for tooth type were molars, incisors, premolars and then canines, respectively; (4) the mean DSRIA was increased with increased age group. We can conclude that the features of naturally progressing alveolar bone loss at the molar and incisor sites in untreated subjects with the AgP and the AP revealed that the mean RABL in the AgP group was faster and greater than those in the AP group.

Keywords: Digital image analysis; Alveolar bone loss; AgP; AP

Abbreviations: RABL: Radiographic Alveolar Bone Loss; AgP: Aggressive Periodontitis; AP: Adult Periodontitis; DSRIA: Digital Scanning Radiographic Image Analysis; CEJ: Cemento-Enamel Junction; LAP: Localized Aggressive Periodontitis; GAP: Generalized Aggressive Periodontitis; EOP: Early onset periodontitis; MIS: Microstation 95 Image Software

\section{Introduction}

Aggressive periodontitis describes a type of periodontal disease and includes two of the seven classifications of periodontitis as defined by the 1999 classification system [1] as localized aggressive periodontitis (LAP)and Generalized aggressive periodontitis (GAP). The majority of the cross-sectional and longitudinal studies employing different techniques relating to the rate of periodontal and radiographic attachment loss and individuals with healthy periodontium, adult periodontitis (AP) and aggressive periodontitis (AgP) have been reported using mainly clinical probing and radiographic measurements [1].
Understanding the epidemiologic study associated with different types of periodontitis, especially in the disease type of AgP and AP among individuals reported to the teaching hospital from retrospective study via a clinical diagnosis. Other reports on the prevalence, distribution and rate of alveolar bone loss have been well carried out based on the longitudinal radiographic evaluation in clinically healthy individuals [2-4]. Only few studies reporting the extent of alveolar bone destruction versus age variance, degree, and location have been documented on patients with periodontitis [5-7]. Recently, Albandar et al. [8] investigated the individuals with 
clinical classifications of periodontitis in adolescent and young adults and suggested that incidental, localized, and generalized early onset periodontitis (EOP) are a heterogeneous group with rapidly and slowly progressing forms. EOP are a heterogeneous group of diseases, sharing several characteristics including early onset and severe periodontal destruction. Tonetti \& Mombelli [9]. They also concluded that a classification system of subsets of the disease that are defined according to a combination of crosssectional criteria and the disease progression may be useful for studies in AgP.

However, it is well been known that little or no information regarding the degree, prevalence, location and extent of alveolar bone levels alterations related to age ranges and sex in Chinese $\mathrm{AP}$ and AgP subjects have been mentioned previously. In addition, our previous studies revealed that there existed a considerable discrepancy of higher prevalence of periodontitis with molar furcation involvement in Chinese than those in Caucasian due to the higher incidence of cervical enamel projections in molars [10] as well as palato-radicular groove in incisors than Caucasian. Literatures regarding the rate of PAL in different aged subjects with established and early onset periodontitis in a cross-sectional and longitudinal studies addressed some great discre- pancies with age and racial variations. The purpose of the present article was to evaluate the periodontal alveolar bone loss rate of the AgP and AP subjects using the digital scanning radiographic image analysis (DSRIA). In addition, RABL related to age groups, sex, tooth type and site in Taiwan Chinese, particularly in the population of AgP and AP was also evaluated.

\section{Materials and Methods}

Study samples were randomly selected from a total of 178 individuals (96 males and 82 females), ranging in age from 24 to 75 years (mean age 43.1 years), with periodontitis reported or referred to the patient population of the Periodontal Clinics of Dental School, Kaoshiung Medical University from 1980 to 1999. The study was conducted to investigate the 178 individuals with $25 \mathrm{AgP}$ and $153 \mathrm{AP}$, respectively, for the past 20 years and to evaluate correlating factors such as periodontal bone loss rate, tooth location, age, tooth mortality and gender change which could influence the clinical characteristics and course. Members of subject population were recalled determining the change and clinical course of AgP and AP patients regardless of whether or not they received periodic periodontal therapy.

The subject population of the present study was limited to the untreated patients, affected with AP and AgP, who never had previously received periodontal therapy. Before any treatment was undertaken patients were subjected to a periodontal special chart and were examined clinically and radio-graphically. The criteria of study samples collection were established and comprised of the following requirements: 1) individuals had never received periodontal treatment (surgical or non-surgical therapy) in the previous dental history; 2) missing tooth extracted was due to periodontal causes; 3) patients had no chronic systemic diseases (such as diabetes, hyper- or hypo-parathyroidism). The clinical examination of periodontal charting comprised of age, sex, questionnaire of dental history (including causes of missing tooth and history of previous periodontal therapy), the scoring of plaque index [10], gingival index [11], initial probing pocket depths and clinical attachment levels. Radiographs, showing tooth distortion, poor radiographic quality, restoration obliterating the cementoenamel junction (CEJ), and overlapping in either teeth or CEJ measurements, which produced measurement points unreadable, were excluded from the study samples.

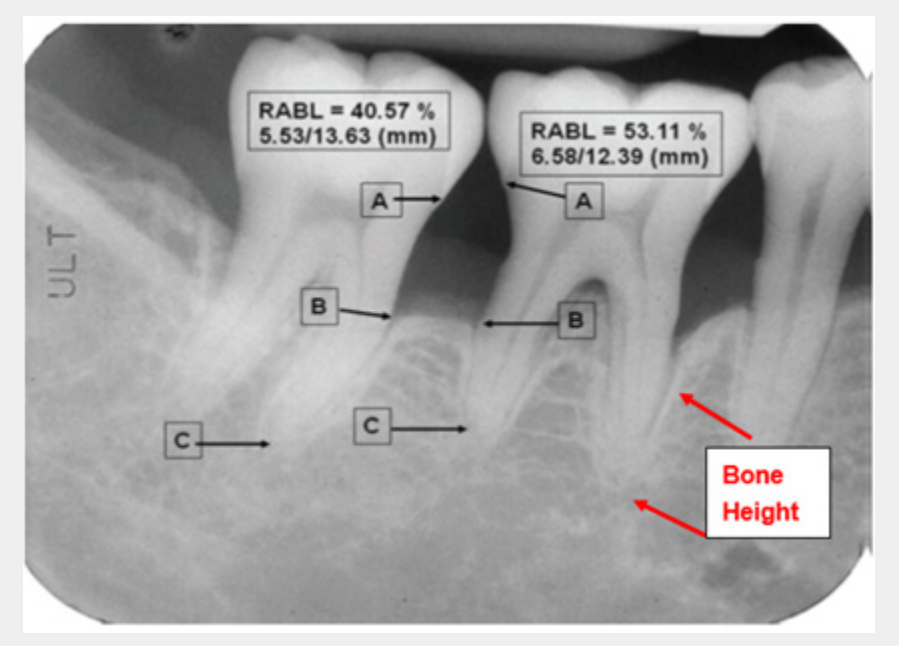

Figure 1: Proximal digital radiographic alveolar bone loss (DRABL) was defined as bone defects of at least $2 \mathrm{~mm}$ distance between the CEJ and the alveolar crest ( $2 \mathrm{~mm}$ under CEJ=A). The radiographic CEJ, alveolar crest (B) and root apex (C) were used as three reference points for calculating $\mathrm{RABL}$.

$\#$ 47: $A B=5.53 \mathrm{~mm} / \mathrm{AC}=13.63 \mathrm{~mm} ; \# 46: A B=6.58 \mathrm{~mm} / \mathrm{AC}=12.39 \mathrm{~mm}$.

$A B / A C=40.57 \% A B / A C=53.11 \%$. 
The radiographic images of the CEJ (A), alveolar crest (B) and root apex (C) were used as three reference points for the calculation of the radiographic linear measurements of RABL. The alveolar bone crest was recorded as the most apical point of each mesial or distal defect. The distance of $A B$ (radiographic alveolar bone loss, RABL), AC (root length) was measured by calculating with the DSRIA to determine the\% of RABL (Figure 1). [12] Duplicate measurements were obtained for each tooth. All the measurements were numerically coded, and results were processed and analyzed by computer system equipped with the MIS [13]. The means of radiographic alveolar bone loss (RABL) in both the AgP and AP were classified into five age groups by age range from $<31,31-40,41-50,51-60$, and $>60$.

\section{Reliability test}

The means of RABL measured by DSRIA for each molar tooth were compared based on the inter- and intra-examiner's data. The means and standard deviations of these measurement data from the DSRIA were used as the statistical value for the comparisons of each molar between the inter- and intra-examiner's groups. The reliability coefficients were used to compare the consistency and reliability between the intra- and the inter-examiner's groups using the DSRIA for each tooth of maxillary, mandibular and of both molars. A statistically significant difference was defined as $\mathrm{p}<0.05$. The reliability coefficient of the intra-examiners' and the inter-examiner's groups in measuring RABL of maxillary, mandibular and of both molars using the DSRIA were ranging between 0.986 and 0.995 , respectively [14]. Comparison of the results between the inter- and intra- examiner's reliability coefficient demonstrated that the inter-class reliability coefficient in maxillary, mandibular, and of both molars was significantly different from zero $(\mathrm{p}<0.001)$.

\section{Data analysis}

The means and standard deviations of the measurement data from the DSRIA for the comparisons of each tooth between the AgP group and AP group were used as the statistical value.

\section{Results}

\section{Mean ABL vs. age groups in maxilla (Table 1)}

Among four age groups in AP, the mean RABL of maxillary teeth increased slightly in the age groups of $31-40$ (33.3 $\pm 10.8 \%)$, $41-50(35.9 \pm 13.0 \%), 51-60(36.8 \pm 11.3 \%)$, while as a great different patterns were documented in age groups of both EOP under $31(42.5 \pm 13.7 \%)$ and AP over 60 years $(29.5 \pm 10.2 \%)$. In particular, individuals with AgP under 31-years age group giving a greater amount of mean RABLs $(42.5 \pm 13.7 \%)$, demonstrated an interesting pattern as compared to any age groups of AP. The greatest amount of mean RABL was identified in either first molars (AP with age 31-40, 49.7 $\pm 19.1 \%$; age 41-50, 51.1 $\pm 20.5 \%$; age $51-60,52.1 \pm 16.6 \%$ ) or second molars (AP with age $31-40$, $35.0 \pm 10.2 \%$; age $41-50,39.8 \pm 12.9 \%$; age $51-60,45.5 \pm 14.8 \%$ ) in any age groups except for age group over 60 years $(33.0 .0 \pm 11.8 \%)$. The mean RABL of individual teeth of the AP group in a descending order of ranking for tooth type, maxillary first molars had the highest percentage, followed by maxillary second molars and maxillary central incisors and then premolars, and canines were the least (Table 1). The means of RABL in the AgP, maxillary first molars $(56.5 \pm 18.2 \%)$ had the highest, followed by lateral incisors $(51.9 \pm 16.9 \%$ central incisors $(49.2 \pm 12.4 \%)$, first premolars (49.5 $\pm 11.7 \%)$, and central incisors $(47.4 \pm 14.7 \%)$, respectively. The finding revealed a remarkably different trend that the means of RABL were greater at the maxillary first molar $(56.6 \pm 18.2 \%)$ and the lateral incisor $(51.9 \pm 16.9 \%)$ in the $\mathrm{AgP}$ as compared to that in any age group of the AP.

Table 1: Difference of mean RABL of tooth type in the maxillary arch of both the AgP and the AP by age groups.

\begin{tabular}{|c|c|c|c|c|c|c|c|c|c|c|}
\hline \multirow{2}{*}{ Tooth Location } & \multicolumn{2}{|c|}{ AgP (age <31) } & \multicolumn{2}{|c|}{ AP (age 31-40) } & \multicolumn{2}{|c|}{ AP (age 41-50) RABL (\%) } & \multicolumn{2}{|c|}{ AP (age 51-60) } & \multicolumn{2}{|c|}{ AP (age >60) } \\
\hline & Mean (SD) & $\mathbf{n}$ & Mean (SD) & $\mathbf{n}$ & Mean (SD) & & Mean (SD) & & Mean (SD) & \\
\hline $17 \& 27$ & $36.9(12.6)$ & 23 & $35.0(10.2)$ & 156 & $39.8(12.9)$ & 65 & $45.5(14.8)$ & 33 & $33.0(11.8)$ & 19 \\
\hline $16 \& 26$ & $56.6(18.2)$ & 22 & $49.7(19.1)$ & 137 & $51.1(20.5)$ & 61 & $52.1(16.6)$ & 37 & $24.3(8.1)$ & 13 \\
\hline $15 \& 25$ & $29.1(10.1)$ & 23 & $31.0(12.1)$ & 146 & $32.2(11.3)$ & 73 & $33.2(10.4)$ & 46 & $34.5(11.6)$ & 22 \\
\hline $14 \& 24$ & $49.5(11.7)$ & 22 & $31.4(11.3)$ & 151 & $36.9(13.4)$ & 74 & $37.6(11.3)$ & 49 & $38.1(13.2)$ & 25 \\
\hline $13 \& 23$ & $31.4(8.3)$ & 23 & $19.9(5.6)$ & 157 & $22.9(7.4)$ & 79 & $23.8(6.7)$ & 51 & $26.7(8.4)$ & 29 \\
\hline $12 \& 22$ & $51.9(16.9)$ & 23 & $29.7(8.4)$ & 142 & $34.4(12.2)$ & 78 & $35.2(10.9)$ & 47 & $24.6(8.3)$ & 28 \\
\hline $11 \& 21$ & $47.4(14.7)$ & 22 & $32.3(9.4)$ & 140 & $38.5(14.9)$ & 73 & $38.8(11.2)$ & 46 & $26.0(9.1)$ & 28 \\
\hline Mean (SD) & $42.5(13.7)$ & 158 & $33.3(10.8)$ & 1029 & $35.9(13.0)$ & 503 & $36.8(11.3)$ & 309 & $29.5(10.2)$ & 164 \\
\hline
\end{tabular}




\section{Mean ABL vs. Age groups in mandible (Table 2)}

For the mean RABL of mandibular teeth, similar trend was also found in the age groups of $31-40$ years (32.8 $\pm 11.3 \%)$, 4150 years $(37.2 \pm 14.3 \%), 51-60$ years $(39.3 \pm 13.5 \%)$ and over 60 years $(43.8 \pm 14.1 \%)$ that mean RABL gradually increased with increasing age. The greatest amount of mean RABL in AP was identified in either first molars or incisors in any age groups. Individuals with AgP under 31-years age group giving a greater amount of mean RABLs $(37.1 \pm 12.7 \%)$ as compared to the AP with age $31-40(32.8 \pm 11.3 \%)$, demonstrated an interesting pattern. A remarkably greater amount of mean RABL for age group over 60 years $(43.8 \pm 14.1 \%)$, as compared to the $\operatorname{AgP}(37.1 \pm 12.7 \%)$ and any age group $(32.8 \pm 11.3 \%$ in age $31-40$ to $39.3 \pm 13.5 \%$ in age 51 60 ) in the AP. A special pattern of greatest amount of mean RABL was noted at the central incisors $(64.6 \pm 19.5 \%)$, lateral incisors (51.6 $\pm 15.7 \%)$, followed by the second molars $(50.2 \pm 16.1 \%)$.

Table 2: Difference of mean RABL of tooth type in the mandobular arch of both the AgP and the AP by age group.

\begin{tabular}{|c|c|c|c|c|c|c|c|c|c|c|}
\hline \multirow{2}{*}{ Tooth Location } & \multicolumn{2}{|c|}{ AgP $($ Age $<31)$} & \multicolumn{2}{|c|}{ AP (Age 31-40) } & \multicolumn{2}{|c|}{ AP (Age 41-50) RABL (\%) } & \multicolumn{2}{|c|}{ AP (Age 51-60) } & \multicolumn{2}{|c|}{ AP (Age >60) } \\
\hline & Mean (SD) & $\mathbf{n}$ & Mean (SD) & $\mathbf{n}$ & Mean (SD) & & Mean (SD) & & Mean (SD) & \\
\hline $37 \& 47$ & $34.8(12.6)$ & 24 & $31.8(12.3)$ & 130 & $38.7(13.1)$ & 69 & $42.9(14.6)$ & 29 & $50.2(16.1)$ & 22 \\
\hline $36 \& 46$ & $51.3(17.2)$ & 22 & $46.6(16.1)$ & 108 & $48.9(17.3)$ & 55 & $49.7(17.8)$ & 33 & $48.7(15.4)$ & 26 \\
\hline $35 \& 45$ & $33.9(11.4)$ & 23 & $26.6(10.7)$ & 148 & $28.6(12.3)$ & 72 & $34.5(12.1)$ & 39 & $33.5(10.2)$ & 27 \\
\hline $34 \& 44$ & $33.8(9.2)$ & 23 & $28.5(7.8)$ & 156 & $30.4(11.1)$ & 74 & $31.2(10.8)$ & 43 & $29.1(10.1)$ & 23 \\
\hline $33 \& 43$ & $30.0(10.1)$ & 24 & $21.2(9.2)$ & 161 & $27.9(10.6)$ & 79 & 29.1(9.7) & 51 & $29.9(11.6)$ & 29 \\
\hline $32 \& 42$ & $42.9(13.5)$ & 22 & $38.3(11.7)$ & 149 & $40.8(16.7)$ & 72 & $42.2(14.5)$ & 47 & $51.6(15.7)$ & 27 \\
\hline $31 \& 41$ & $49.2(12.4)$ & 19 & $39.7(12.6)$ & 143 & $41.8(18.9)$ & 63 & $48.0(16.7)$ & 41 & $64.6(19.5)$ & 26 \\
\hline Mean (SD) & $37.1(12.7)$ & 157 & $32.8(11.3)$ & 995 & $37.2(14.3)$ & 484 & $39.3(13.5)$ & 283 & $43.8(14.1)$ & 180 \\
\hline
\end{tabular}

The mean RABL of individual teeth of the AP group in a descending order of ranking for tooth type, first molars had the highest percentage, followed by central and lateral incisors and then second molars, canines were the least except for age group over 60 .

\section{Difference of mean rabl in maxilla and mandible (Table $1 \& 2)$}

The means RABL were remarkably higher in maxilla than those in mandible in each age group except age group over 60 years. In addition, the mean RABL at incisors were remarkably higher in mandible when compared to the maxilla irrespective of any age groups except age group under 31 years in AgP. The amount of mean RABL at molar sites was greater in the maxilla in any age groups with AgP and AP except for age group with AP over 60 years, whereas the mean RABL at incisor sites was greater in the mandible as compared to those in the maxilla with an exception for the AgP group. The mean RABL of individual teeth in both arches revealed, in majority, a descending order of ranking for tooth type, maxillary first molars had the highest percentage, followed by maxillary second molars and mandibular central incisors and then premolars, canines were the least except for age group over 60 in the mandible.

Distribution and prevalence of teeth mortality of the AgP and the AP in both maxillary arch by age group (Table 3 \& 4)

Table 3 revealed that the tooth mortality rate was higher in the molars and incisors than those in other teeth in both arches. In general, tooth mortality rate tended to increase with increasing age in both arches. The highest tooth mortality rate was found in the age group over 60 years, especially in the maxillary first $(59.4 \%)$ and second $(40.6 \%)$ molars. The highest tooth mortality rate of mandibular teeth was noted in the age group of 51-60 years. Based on the tooth type, the increase in the number of teeth loss with increasing age was most pronounced in the maxillary first and second molars accounted for $4.2 \%$ to $40.6 \%$ and $8.3 \%$ to $59.4 \%$, respectively, from the five age groups of untreated patients with the AgP and the AP. Table 4 showed a higher tooth mortality rate was in the mandibular teeth than those in the maxillary one. 


\section{Advances in Dentistry \& Oral Health}

The descending order of ranking by frequency of tooth loss was documented in Table 4. The mandibular second molars (46.3\%) were the teeth most frequently lost, followed by the maxillary second molars (40.5\%), the mandibular first molars (38.9\%) and then the maxillary second premolars (31.3\%) and the mandibular first premolars (28.1\%), and incisors, respectively. Canines were the lowest mortality rate.

Table 3: Distribution and prevalence of teeth mortality of the AgP and the AP in the maxillary arch by age group.

\begin{tabular}{|c|c|c|c|c|c|}
\hline \multirow{3}{*}{ Tooth Location } & \multicolumn{5}{|c|}{ Teeth Loss } \\
\hline & AgP Age $<31$ & AP Age $31-40$ & AP Age 41-50 & AP Age 51-60 & AP Age $>60$ \\
\hline & $\mathrm{n} / 24^{*}(\%)$ & n/164 (\%) & n/82 (\%) & n/54 (\%) & n/32 (\%) \\
\hline $17 \& 27$ & $1(4.2)$ & $8(4.9)$ & 17 (20.7) & 21 (38.9) & $13(40.6)$ \\
\hline $16 \& 26$ & $2(8.3)$ & $27(16.5)$ & $21(25.6)$ & 17 (31.5) & $19(59.4)$ \\
\hline $15 \& 25$ & $1(4.2)$ & $18(11.0)$ & $9(11.0)$ & $8(14.8)$ & $10(31.3)$ \\
\hline $14 \& 24$ & $2(8.3)$ & $13(7.9)$ & $8(9.8)$ & $5(9.3)$ & 7 (21.9) \\
\hline $13 \& 23$ & $1(4.2)$ & $7(4.3)$ & 3 (3.7) & $3(5.6)$ & $3(9.4)$ \\
\hline $12 \& 22$ & $1(4.2)$ & $22(13.4)$ & $4(4.9)$ & $7(13.0)$ & $4(12.5)$ \\
\hline $11 \& 21$ & $2(8.3)$ & $24(14.6)$ & $9(11.0)$ & $8(14.8)$ & $4(12.5)$ \\
\hline
\end{tabular}

Table 4: Distribution and prevalence of teeth mortality of the AgP and the AP in the mandibular arch by age group.

\begin{tabular}{|c|c|c|c|c|c|}
\hline \multirow{3}{*}{ Tooth Location } & \multicolumn{5}{|c|}{ Teeth Loss } \\
\hline & $A g P<31$ & AP $31-40$ & AP 41-50 & AP 51-60 & $\mathrm{AP}>60$ \\
\hline & $\mathrm{n} / 24^{*}(\%)$ & n/164 (\%) & n/82 (\%) & n/54 (\%) & n/32 (\%) \\
\hline $37 \& 47$ & $0(0)$ & 34 (20.7) & $13(15.9)$ & $25(46.2)$ & $10(31.3)$ \\
\hline $36 \& 46$ & $2(8.3)$ & $56(34.1)$ & 27 (32.9) & 21 (38.9) & $6(18.8)$ \\
\hline $35 \& 45$ & $1(4.2)$ & $16(9.8)$ & $10(12.2)$ & $15(27.8)$ & $5(15.6)$ \\
\hline $34 \& 44$ & $1(4.2)$ & $8(4.9)$ & $8(9.8)$ & $11(20.4)$ & $9(28.1)$ \\
\hline $33 \& 43$ & $0(0)$ & $3(1.8)$ & $3(3.7)$ & $3(5.6)$ & $3(9.4)$ \\
\hline $32 \& 42$ & $2(8.2)$ & $15(9.2)$ & $10(12.2)$ & $7(13.0)$ & $5(15.5)$ \\
\hline $31 \& 41$ & $5(20.8)$ & $21(12.8)$ & $19(23.2)$ & $13(24.1)$ & $6(18.8)$ \\
\hline
\end{tabular}

\section{Discussion}

Pilot study indicated that the DSRIA resulted in a high value of correlation coefficients in the intra-examiner's $(r=0.995$ and $0.996, \mathrm{p}<0.001$, respectively) and inter-examiner's( $\mathrm{r}=0.995$ and $0.994, \mathrm{p}<0.001)$ reliability test to measure the alveolar bone loss. Therefore, by using the DSRIA to assess the proximal alveolar bone loss in the present study, we were able to get more accurate values of RABL as compared to those used by traditional methods that were reported earlier [2- 5]. In general, the observations from our study the greatest amount of mean RABL in either arch or mandibular incisors alone were noted. Similar findings have been well documented in other studies [14-21]. Therefore, our results, however, supported the earlier agreement that the molars and incisors are the most susceptible teeth risking for the periodontal breakdown. Based on the general agreement of teeth affected most risk for the greatest amount of mean RABL, however, it is necessary that the clinician should pay more attention to the most important sites, particularly molars and incisors at each recall appointment. In contrast, earlier finding of the lowest rate of bone loss in the mandibular molar that was reported by Papapanou
[19] was also documented.

In comparison to the four age groups of the AP in maxillary arches, the mean RABL gradually increased with increasing age groups in the present study except for age over 60. Similar tendency was also observed in the mandibular arch. This finding revealed a positive relationship between mean RABL and increasing age that agreed well with most other reports $[1,16,19,20,22]$. Regarding the first interesting pattern under 31 years age group (AgP group) revealed significant greater mean RABL in the maxilla $(42.5 \pm 13.7 \%)$ when compared to another four age groups (from $29.5 \pm 10.2 \%$ to $36.8 \pm 11.3 \%$ ) (Table 1 ). The possible reason may be partly due to some subjects with susceptive AgP including in this small sample size. Our charts revealed that 5 subjects with the most severe alveolar bone loss at all teeth with molars and incisors being most severely affected RABL in subjects under 31 years age group (AgP group). In contrast, other 8 subjects revealed a stable localized pattern of typical AP. Some other studies [23$25]$ also pointed to a largely generalized disease in the 20-30 years range and concluded that the disease rapidly developed generalized destruction with increasing age. 
Our results from this interesting bone loss pattern under 31 years appeared to be agreement in part with that concept, as the age of present subjects with AgP was greater as compared to the localized pattern of juvenile periodontitis (LJP) age onset at 12) and adult periodontitis (age over 31) [24-26]. Based on the present data, the mean RABL of maxilla in either first molars or lateral incisors being much more severely affected under 31 years age group (AgP group) when compared to another four age groups This pattern of disease progression in this sample, indicated by the cross-sectional results were well in agreement with conclusions documented by Okamoto et al. [19]; Lindhe et al. [26] that advanced periodontal disease was confined to few sites in the younger age groups (AgP group) [25], whereas the disease had a more generalized character in older subjects. Alternately, another possible explanation for the significant smaller mean RABL in the age group over 60 years may be partly due to a higher frequency of guarded teeth with greatest mean RABL were already extracted except due to small sample size. The greater tooth mortality rate may also explain the problem that i.e. the less alveolar bone loss, the more teeth loss in molars and incisors of maxilla with respect to the age group over 60 years.

Regarding the rate of tooth mortality, the percentages of teeth most frequently missing was mandibular first molars (31.5\%) and then maxi- llary first molars $(24.2 \%)$ and mandibular second molars (23.0\%). Results also revealed that tooth mortality rate was lowest in canines as compared to the other teeth. These results were in general agreement with those reported by Becker et al. [27]; Rohner et al. [17]. The results of tooth mortality and age groups, in general, documented a gradually increasing tooth loss rate with increasing age group in any tooth sites of maxillary teeth. Similar pattern of tooth loss rate for age groups was found in mandibular teeth, but highest tooth loss rate was noted at the second (46.2\%) and first (38.9\%) molars for the 51-60 age group instead of the age group over 60 years. This result indicated that majority of teeth loss, due to periodontal origin, were noted on the mandibular molars and central incisors during the period of 51-60 years. This finding, however, in general, agreement with the report documented by Becker et al. [27]. The possible explanation for the higher tooth loss rate of mandibular molars in the age group of 5160 years than the maxillary molars in the age over 60 years may be that mandibular molars with two roots had less resistant to tooth loss than maxillary molars with three roots under a similar mean RABL. The teeth lost in individuals with non-periodontal causes were excluded from the study samples. So, the present study seems to be likely to reflect tooth mortality rate associated with periodontitis. This finding, however, also indicates that periodontitis is the most important reason resulted in the early loss of teeth. Results are in agreement with other reports that were concluded as the rate of periodontal destruction reaches a peak around 51-60 years of age and thereafter is reduced $[28,29]$.

Although, it is well been known that radiographic method is not an accurate measurement for interproximal RABL, but on the other hand, the reliability, validity and relatively specificity had been shown to be of essential importance. Especially, the combined use of the standardized paralleling radiographic technique with Eggen film holders to assess the clinical measurements of the alveolar bone levels was useful in either cross-sectional epidemiological or longitudinal follow-up survey [29-31]. Still, there are some other advantages mentioned by Salonen et al. [22] that it is possible to control the reproducibility of the diagnostic interpretation over time for the longitudinal follow-up survey. The variation in the beam projection that resulted in the foreshortening or elongation of radiographic image can be effectively minimized by using\% of the ratio of inter-proximal RABL to the root length or tooth length measured from the periapical radiograph [30,32,34]. In addition, the relatively constant relationship between tooth and root length was also documented [20].

The current finding of alveolar bone defect in the various age groups documented that bony defects generally increase with age and is in general agreement with others $[19,33,34]$. The special pattern of mean RABL in the present study reaches a peak around 51- 60 years of age. This finding is generally in consistent with most investigators, $[29,30]$ they have documented the rate of periodontal destruction gets a highest peak around 51-60 year of age. This study also documented the data of tooth mortality rate showed that a tendency of decreasing order of ranking by frequency of tooth loss is in consistent with the decreasing order of ranking by mean RABL in either tooth type or either arch. A special finding, for the highest mortality rate associated with a sudden decrease in the mean RABL at the age group over 60 , strongly indicated and explained that adult periodontitis seems to be the most important cause between tooth loss and mean RABL in our study samples. This conclusion, however, is generally in accordance with recent reports documented by other investigators $[19,20,30,31]$ i.e., the higher the number of tooth loss, the more the mean RABL when the mean RABL of missing teeth was included in the pooling sample.

The periapical radiographs were taken by the use of a parallel technique and XCP film holders with long cone indicator. Radiographic assessments of mesially and distally alveolar bone loss, made on the radiographs (10-magnification), were recorded by a scanner (Nikon LS-1000, Adaptec AHA-2940 UW SCSI card) at $1350 \mathrm{dpi}$ (dots / inch) and 256 shades of gray scale. All the scanned radiographs were displayed on a PC monitor under a 10x image enlargement and measured by personal computer system (Microsoft Windows 98; Adobe Photoshop 5.0) equipped with the Microstation 95 Image Software (MIS) (Windows x 86, Bently Systems, Inc., USA). The proximal radiographic alveolar bone loss (RABL) was defined as bone defects and that the distance between $\mathrm{CEJ}$ and $\mathrm{AC}$ should be at least $2 \mathrm{~mm}$. The radiographic measurement of each tooth was measured mesially and distally, in $\mathrm{mm}$. 


\section{References}

1. Armitage GC (1999) Development of a classification system for periodontal diseases and conditions. Ann Periodontol 4(1): 1-6.

2. Boyle WD, Via WF, McFacc WT (1973) Radiographic analysis of alveolar crest height and age. J Periodontol 44(4): 236-242.

3. Strahan JD (1965) Relation of the mucogingival junction to alveolar bone margin. Academy Rev 13(1): 23-28.

4. Oconner TW, Biggs NL (1965) Interproximal bony contours. J Periodontol 35(4): 326-330.

5. Selikowitz HS, Sheiham A, Albert D, Williams GM (1981) Retrospective longitudinal study of the rate of alveolar bone loss in humans using bite-wing radiographs. J Clin Periodontol 8(5): 431-438.

6. Suomi JD, Plumo J, Barbano JP (1968) A comparative study of radiographs and pocket measurements in periodontal disease evaluation. J Periodontol 39(6): 311-315.

7. Manson JD, Nicholson K (1974) The distribution of bone defect in chronic periodontitis. J Periodontol 45(2): 88-92.

8. Albander JM, Brown LJ, Genco RJ, Löe H (1997) Clinical classification of periodontitis in adolescents and young adults. J Periodontol 68(6): 545-555.

9. Tonetti M, Mombelli A (1999) Annals of Periodontology. Early-onset periodontitis $4(1)$.

10. Hou GL, Tsai CC (1987) Relationship between periodontal furcation involvement and molar cervical enamel projection. J Periodontol 58(10): 715-721.

11. Hou GL, Tsai CC (1993) Relationship between palato-radicular groove and localized periodontitis. J Clin Periodontol 20(9): 678-682.

12. Hou GL (2020) Annually Radiographic Periodontal Bone Loss Rates of Tooth Affected Severe Advanced Periodontitis with Secondary Occlusal Traumatism. Intern J Dent \& Oral Health 6(6): 1-5.

13. Silness J, Loe H (1964) Periodontal disease in pregnancy. ?. Correlation between oral hygiene and periodontal condition. Acta Odontol Scand 22: 121-135.

14. Loe H, Silness J (1963) Periodontal disease in pregnancy. 目. Prevalence and severity. Acta Odontol Scand 21: 533-551.

15. Lin CH, Hou GL, Tsai CC, Yang YH, Shieh TY (2000) Relationship among occlusal attritions, chewing habit and clinical attachment loss in mandibular molars. J Dent Res, p. 579.

16. Hou GL, Lin CH, Hung CH, Yang YH, Shieh TY, et al. (2000) The consistency and reliability of periodontal bone level measurements using digital scanning radiographic image analysis - A pilot study. Kaohsiung J Med Sci 16(11): 566-573.

17. Rohner F, Cimosoni G, Vuagnat P (1983) Longitudinal radiographical study on the rate of alveolar bone loss in patient of a dental school. J Clin Periodontol 10(6): 643-651.

18. Schei O, Waerhaug J, Lovdal A, Arno A (1959) Alveolar bone loss as related to oral hygiene and age. J Periodontol 30(1): 7-16.
19. Okamoto H, Yoneyama T, Lindhe J, Haffajee AD, Socransky SS (1988) Methods of evaluating periodontal disease data in epidemiological research. J Clin Periodontol 15(7): 430-439.

20. Loe H, Anerud A, Boysen H, Smith M (1978) The nature history of periodontal disease in man. The rate of periodontal destruction before 40 year of age. J Periodontol 49(1): 607-620.

21. Papapanou PN, Wennatrom JL, Grondahl (1988) Periodontal status in relation to age and tooth type. A cross-sectional radiographic study. J Clin Periodontol 15(7): 469-478.

22. Salonen LWE, Frithiof L, Wrouters FR, Hellden LB (1991) Marginal alveolar bone height in an adult Swedish population: A radiographic cross-sectional epidemiologic study. J Clin Periodontol 18(4): 223-232.

23. Gjermo P, Bellini HT, Santos VP, Santos VP, Martins JG, et al. (1984) Prevalence of bone loss in a group of Brazilian teengers assessed on bite-wing radiographs. J Clin Periodontol 11(2): 104-113.

24. Van der Velden U (1984) Effect of age on the periodontium. J Clin Periodontol 11(5): 281-294.

25. Hormand J, Frandsen A (1979) Juvenile periodontitis: Localization of bone loss in relation to age, sex, and teeth. J Clin Periodontol 6(6): 407416.

26. Lindhe J, Okamato H, Haffajee A, Socransky SS (1989) Periodontal loser sites in untreated adult subjects. J Clin Periodontol 16(10): 671-678.

27. Becker W, Berg L, Becker B (1979) Untreated periodontal disease: A longitudinal study. J Periodontol 50(5): 234-244.

28. Albandar JM, Abbas DK, Waerhaug M, Gjermo P (1985) Comparison between standardized periapical and bitwing radiographs in assessing alveolar bone loss. Commu Dent Oral Epidem 13(4): 222-225.

29. Wouters FR, Lavstedt S, Frithiof L, Soder PO, Hellden L, et al. (1988) A computerized system to measure interproximal alveolar bone levels in epidemiological radiographic investigations. II. Intra- and interexaminer variation study. Acta Odon Scand 46(1): 33-39.

30. Wouters FR, Jon-And C, Frithiof L, Sober PO, Lavstedt S (1988) A computerized system to measure interproximal alveolar bone levels in epidemiological radiographic investigations. I. Methological study. Acta Odont Scand 46(1): 25-31.

31. Eggen S (1969) Standardized projection technique in intra-oral roentgeno- graphy. Sven Tandlakar Tidn 61: 768-872.

32. Rise J, Albandar JM (1988) Pattern of alveolar bone loss and reliability of measurements of the radiographic technique. Acta Odont Scand 46(4): 227-232.

33. Goodson JM, Haffajee AD, Socransky SS (1984) The relationship between attachment loss and alveolar bone loss. J Clin Periodontol 11(5): 348-359.

34. Nielsen IM, Glavind L, Karring T (1980) Interproximal periodontal intra-bony defects. Prevalence, localization, and etiological factors. J Clin Periodontol 7(3): 187-198. 

(C) Commons Attribution 4.0 License

DOI: 10.19080/ADOH.2020.13.555870

\section{Your next submission with Juniper Publishers} will reach you the below assets

- Quality Editorial service

- Swift Peer Review

- Reprints availability

- E-prints Service

- Manuscript Podcast for convenient understanding

- Global attainment for your research

- Manuscript accessibility in different formats

( Pdf, E-pub, Full Text, Audio)

- Unceasing customer service

Track the below URL for one-step submission https://juniperpublishers.com/online-submission.php 